University of South Carolina

Scholar Commons

$5-1-2008$

\title{
Novel Wideband Directional Dipole Antenna on a Mushroom Like EBG Structure
}

\author{
Mohammed Z. Azad \\ Motorola,Inc., azad@motorola.com \\ Mohammod Ali \\ University of South Carolina - Columbia, alimo@engr.sc.edu
}

Follow this and additional works at: https://scholarcommons.sc.edu/elct_facpub

Part of the Electrical and Computer Engineering Commons

Publication Info

Published in IEEE Transactions on Antennas and Propagation, Volume 56, 2008, pages 1242-1250. http://ieeexplore.ieee.org/xpl/Recentlssue.jsp?punumber=8

(c) 2008 by IEEE

This Article is brought to you by the Electrical Engineering, Department of at Scholar Commons. It has been accepted for inclusion in Faculty Publications by an authorized administrator of Scholar Commons. For more information, please contact digres@mailbox.sc.edu. 


\title{
Novel Wideband Directional Dipole Antenna on a Mushroom Like EBG Structure
}

\author{
Mohammed Ziaul Azad, Student Member, IEEE, and Mohammod Ali, Senior Member, IEEE
}

\begin{abstract}
A new method to design thin wideband directional dipole antennas on electromagnetic bandgap (EBG) structure is introduced. At the heart of this method is the idea to understand and properly utilize the complex interactions between the dipole impedance and the EBG reflection phase characteristics. Using the proposed technique a thin wideband printed dipole is designed, fabricated and tested. The antenna can satisfy applications, such as Digital Communication System (DCS, 1.71-1.88 GHz), Global System for Mobile Communication (GSM, 1.85-1.99 GHz), Personal Communication System (PCS, 1.85-2.05 GHz), Universal Mobile Telecommunication System (UMTS, 1.92-2.17 GHz) and Wireless Local Area Network (WLAN, 2.4-2.485 GHz) within VSWR $\leqslant 2.5: 1$. Antenna peak gain varies from 5.5 to $8.3 \mathrm{dBi}$ from 1700 to $2500 \mathrm{MHz}$ while the front to back $(\mathrm{F} / \mathrm{B})$ ratio is higher than $15 \mathrm{~dB}$ for an overall antenna size of $102 \mathrm{~mm}$ by 76.4 mm by $5.9 \mathrm{~mm}$.
\end{abstract}

Index Terms-Antenna, balun, electromagnetic bandgap (EBG), wideband.

\section{INTRODUCTION}

$\mathbf{P}$ LANAR, thin low profile antennas are in great demand for mobile handheld terminals as well as for base stations and radar. Many applications also require wide impedance and pattern bandwidths as well as directional patterns. Wide bandwidth can be achieved by designing a wide slot, fat dipole or bowtie dipole. However, when such antennas are printed on a thin grounded dielectric substrate to achieve directional patterns the bandwidth suffers serious degradation. Similarly, microstrip patch antennas although provide directional patterns, are generally narrow band. Wideband patches such as the E-shaped patch [1] require relatively large antenna height (about $14 \mathrm{~mm}$ for a 2 $\mathrm{GHz}$ antenna) and foam as the substrate material. Such substrate material makes it difficult to design and develop printed antenna arrays which require printed transmission lines.

The focus of this paper is to explore the prospects of designing a wideband directional dipole antenna on a thin dielectric substrate. Clearly the dipole having being only one dimensional (if width is ignored) many more of them can be accommodated within a small area to develop an array. A thin printed antenna will reduce the size and weight of the substrate. And

Manuscript received June 7, 2007; revised October 17, 2007. This work was supported in part by the National Science Foundation (NSF) Career Award ECS0237783

The authors are with the Department of Electrical Engineering, University of South Carolina, Columbia, SC 29208 USA (e-mail: azad@engr.sc.edu; alimo@engr.sc.edu).

Digital Object Identifier 10.1109/TAP.2008.922673 finally a wideband printed antenna with directional characteristics could support a number of applications using the same antenna.

Theoretically, a dipole antenna when placed parallel to a ground plane at a distance of $\lambda / 4$ should radiate efficiently [2], [3]. But satisfying the $\lambda / 4$ distance is quite difficult, particularly at the lower $\mathrm{GHz}$ frequencies and with low dielectric constant substrates. A thick substrate also generates undesirable non-radiating surface waves, which extract power from the direct radiation pattern, resulting in increased side-lobe levels and a decrease in efficiency. To solve these problems researchers have proposed the use of electromagnetic bandgap (EBG) structures with dipole antennas [4], [5]. Significant progress has been made in the last decade on understanding and predicting the bandgaps of $2 \mathrm{D}$ or $3 \mathrm{D}$ periodic materials and their integration with antennas for surface wave suppression [6]-[22]. In [6], a compact low profile antenna on an EBG structure was introduced for the use in a cordless handset to achieve high efficiency (80\%). The authors of [13] have shown that a variable length dipole antenna on an EBG structure shows good impedance match when the EBG reflection phase is within the range of $90 \pm 45$ degrees. The authors of [15] have introduced the concept of computing the driving point impedance of a dipole antenna lying parallel to a mushroom like EBG surface and then showed that such a dipole has a dual band VSWR characteristic.

Much of the studies conducted in the literature focuses on directional dipole antennas on EBG structures which have narrow impedance bandwidths. By contrast, the focus of this paper is to explore the prospects of designing a thin wideband directional dipole antenna on an EBG structure primarily for application in mobile communication base stations and other wideband fixed wireless terminals. We consider the frequency range of 1.6-2.5 $\mathrm{GHz}$ which includes a number of applications, such as Digital Communication System (DCS, 1.71-1.88 GHz), Global System for Mobile Communication (GSM, 1.85-1.99 GHz), Personal Communication System (PCS, 1.85-2.05 GHz), Universal Mobile Telecommunication System (UMTS, 1.92-2.17 GHz) and IEEE $802.11 \mathrm{~b}(2.4-2.485 \mathrm{GHz})$. Based on our previous work on EBG assisted thin dipole antenna [15] we study the interaction between the dipole antenna and the complex reflection phase of the EBG structure. Considering a simple real and image dipole and their self and mutual impedances we perform an optimization process. The goal is to find an EBG structure that can provide an antenna bandwidth of 1.7-2.5 GHz within 2.5:1 VSWR. The only time a full wave numerical simulation is performed is when the dipole self and mutual impedances are computed. The whole optimization process is based on simple algebraic equations and can be easily computed in Matlab. The alternative is 


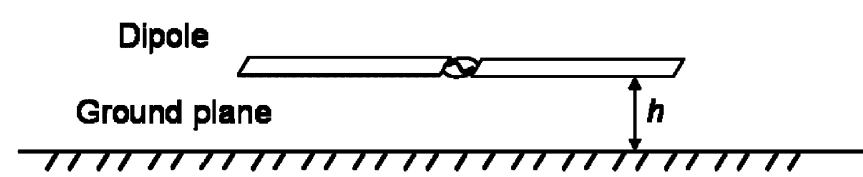

Primary dipole

(a)

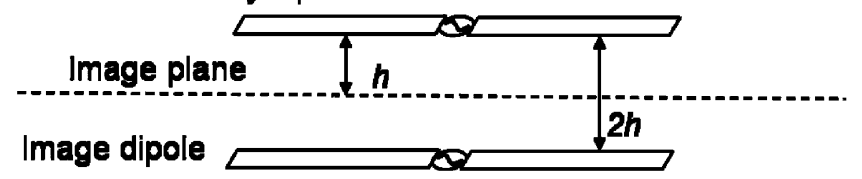

(b)

Fig. 1. (a) A horizontal dipole antenna operating against a ground plane and (b) equivalent representation.

to design an antenna and EBG combination by trial and error which can be very tedious. Once the optimized EBG parameters are identified the antenna is simulated.

\section{BASIC PRINCIPLE}

Consider a horizontal dipole antenna operating against a ground plane at a height $h$. Applying image theory such an antenna can be modeled as an assembly of a primary and an image dipole as shown in Fig. 1, [3]. The driving-point impedance, $Z_{d}$ of the original antenna shown in Fig. 1(a) can be calculated from the self-impedance, $Z_{11}$ of the primary dipole and the mutual impedance, $Z_{21}$ between the primary and the image dipoles. The underlying assumption in such a case is that the ground plane is perfectly conducting and is of infinite extent.

The driving-point impedance of the original dipole shown in Fig. 1(a) can be calculated as [15]

$$
Z_{d}=Z_{11}+Z_{21} e^{j \theta}
$$

where $\theta$ is the reflection phase angle which is $180^{\circ}$ for the case depicted in Fig. 1(a).

Compared to metallic ground planes EBG structures provide a frequency dependant reflection phase, $\theta$ characteristics. Intuitively it is easy to appreciate that suitable values of $Z_{d}$ can be obtained by exploring the interactions between the reflection phases of an EBG with the antenna's impedance. When a dipole is placed on an EBG the question that arises is which EBG structure will give the best reflection phase profile so that a wide bandwidth (impedance and gain) and good radiation characteristics can be obtained. To synthesize an EBG assisted dipole, it is possible to typically design an EBG structure and place it together with a dipole and study the antenna performance, such as VSWR, pattern and gain by performing numerical simulation or experimental measurements. If satisfactory performance is not achieved, a new modified EBG structure should be designed and the antenna plus EBG should be re-simulated. This trial and error process can be tedious. Instead in this paper we propose a new simple design methodology.

But first let us consider a very few basic cases. Consider a dipole antenna printed on a $94 \mathrm{~mm}$ by $94 \mathrm{~mm}$ by $4.5 \mathrm{~mm}$ TMM

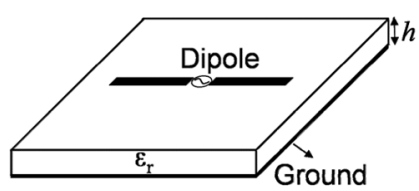

(a)

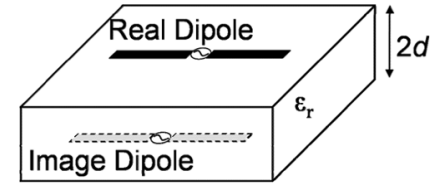

(b)
Fig. 2. (a) Dipole antenna printed on a grounded dielectric substrate and (b) two dipoles on the top and bottom of an ungrounded dielectric substrate.

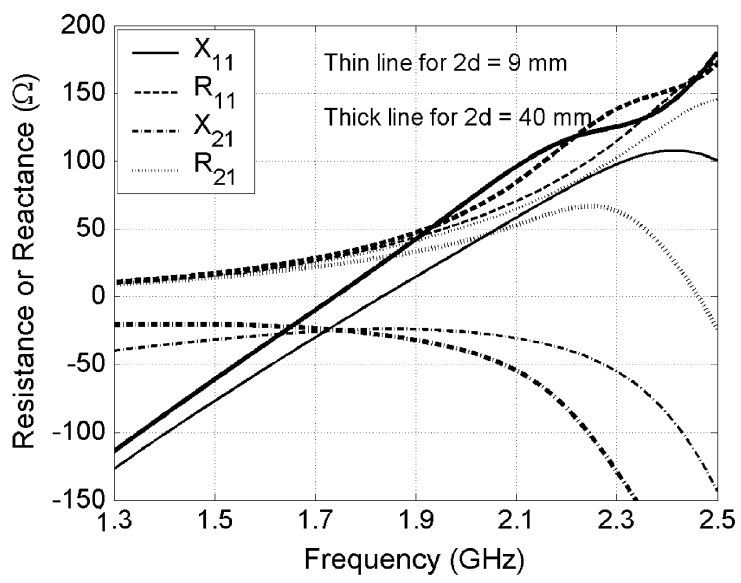

Fig. 3. Computed self and mutual impedance of dipoles shown in Fig. 2(b); 2 $d=9 \mathrm{~mm}$ and $40 \mathrm{~mm}$

$\left(\epsilon_{r}=4.5\right)$ substrate [Fig. 2(a)]. The length and width of the antenna are $47 \mathrm{~mm}$ and $1 \mathrm{~mm}$, respectively. An equivalent of the antenna is shown in Fig. 2(b). Input $S_{11}$ (dB) data of the printed antenna shown in Fig. 2(a) were computed using HFSS. Similarly, the self and mutual impedances, $\left(Z_{11}\right.$ and $\left.Z_{21}\right)$ of the two antennas were also computed for $2 d=9 \mathrm{~mm}$ and $40 \mathrm{~mm}$. Fig. 3 shows the impedance data for $2 d=9 \mathrm{~mm}$. Considering $\theta=180^{\circ}$ in (1) for metal, the driving point impedance $\left(Z_{d}\right)$ for the equivalent case was calculated. Input $S_{11}(\mathrm{~dB})$ data were computed with reference to a $50 \Omega$ feed.

Results of four such cases are shown in Fig. 4. Cases 1 and 2 represent a separation of $9 \mathrm{~mm}$ and $40 \mathrm{~mm}$ between the two dipoles shown in Fig. 2(b). For comparison the exact $S_{11}$ data for the antenna shown in Fig. 2(a) were also computed and are shown as cases 3 and 4 in Fig. 4 . Case 3 should be compared with case 1 while case 4 should be compared with case 2 . The resonant frequency of the dipole without ground plane is $1.85 \mathrm{GHz}$. The mutual resistance $R_{21}$ is similar to the self resistance $R_{11}$. The mutual reactance $X_{21}$ is nearly constant for a frequency of upto $2.2 \mathrm{GHz}$ but beyond that it increases rapidly. Observing the quantities in Fig. 3 it is plausible that good impedance matching can be obtained within 1.6-2.4 GHz. Below $1.6 \mathrm{GHz}$ the resistances are too small. Above $2.4 \mathrm{GHz}$ all the quantities are probably too large. Clearly the analysis technique described in (1) has good agreement with the numerical results obtained directly from HFSS. For instance, cases 1 and 3 compare very well. Cases 2 and 4 also compare well except that there is a small difference in the operating centre frequency. This might be because of the relatively large separation between the antennas. 


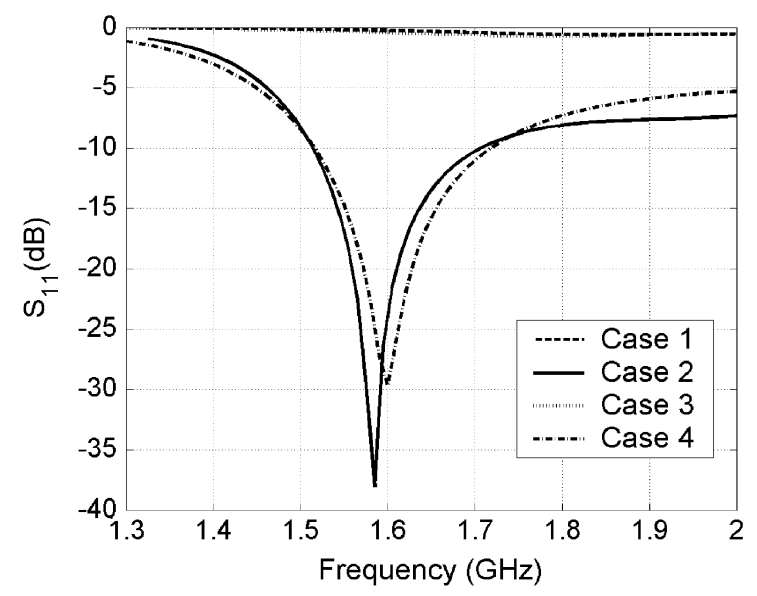

Fig. 4. Comparing the $S_{11}$ data for four cases.

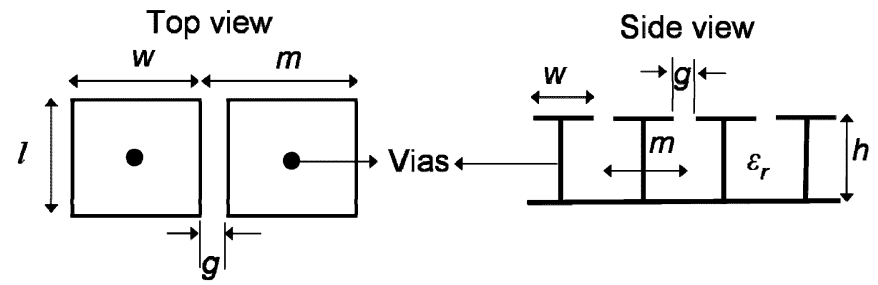

Fig. 5. Geometrical parameters of a mushroom-like EBG.

\section{Reflection Phase of A Mushroom LiKe EBG STRUCTURE}

The geometry of a mushroom like EBG structure is shown in Fig. 5. The structure consists of a periodic array of metal plates printed on a dielectric substrate. Each metal plate is connected to the ground plane using a metal via. For simplicity, we consider square metal plates of the same size and vias with the same diameter. The reflection phase of such a structure varies from $180^{\circ}$ to $-180^{\circ}$ as a function of frequency. The reflection phase $(\theta)$ is given by [4]

$$
\theta(f)=\operatorname{Im}\left[\ln \left(\frac{a f^{2}+j b f-\eta}{-a f^{2}+j b f+\eta}\right)\right]
$$

where $f$ is the frequency, $\eta$ is the intrinsic impedance of freespace $(377 \Omega$ ) and $a$ and $b$ are the EBG design parameters. The parameters $a$ and $b$ are defined as

$$
a=4 \pi^{2} \eta L C, \quad b=2 \pi L
$$

where $L$ and $C$ are the inductance and capacitance of a unit cell of the EBG structure. The inductance $L$ depends on the thickness, $h$ of the EBG structure and the capacitance $C$ depends on the fringing electric fields between the pairs of metal plates. These are given by

$$
\begin{aligned}
L & =\mu h \\
C & =\frac{w\left(\varepsilon_{1}+\varepsilon_{2}\right)}{\pi} \cosh ^{-1}\left[\frac{m}{g}\right]
\end{aligned}
$$

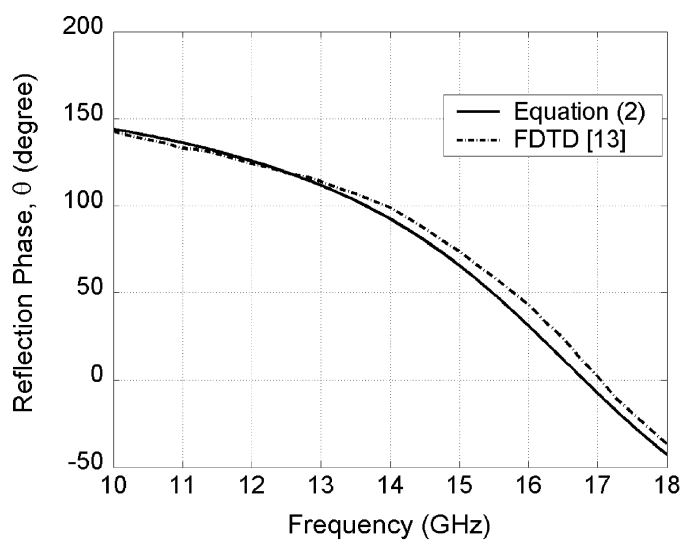

(a)

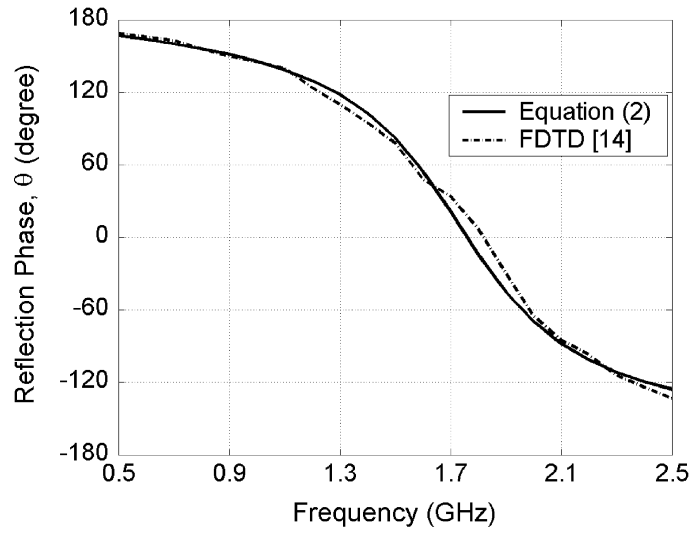

(b)

Fig. 6. EBG reflection phase data using (2) are compared with FDTD simulation results obtained from [13] and [14].

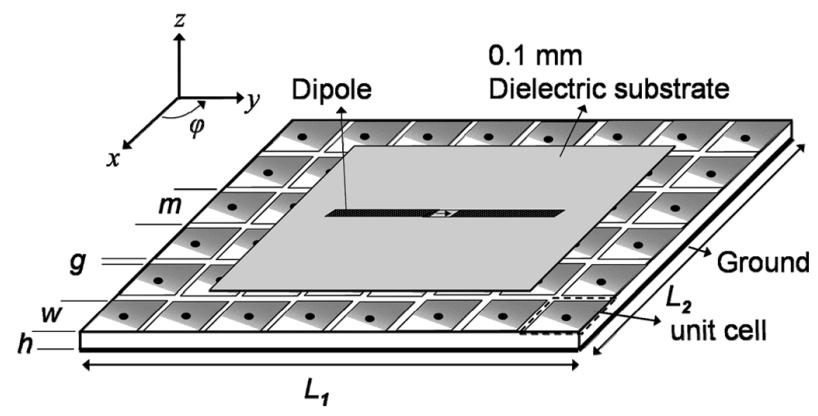

Fig. 7. Schematic of EBG with dipole.

where $w$ is the width of a square metal plate, $g$ is the gap between the plates and $m$ is the EBG period.

The dielectric constant of the substrate containing the EBG structure is $\epsilon_{1}$. The dielectric constant of the surrounding medium is $\epsilon_{2}=1$ which represents air. Reflection phase data of the EBG structure can be calculated as a function of frequency by varying the parameters $a$ and $b$ which in turn are governed by the actual EBG geometrical parameters as defined in (3)-(5). Such reflection phase data of two mushroom type EBG structures described in [13] and [14] were calculated using (2). These data are compared with the results obtained from finite difference time domain (FDTD) simulations [13], [14] in Fig. 6. The results obtained using (2) agree very well with the FDTD data obtained from [13] and [14]. Only minor 


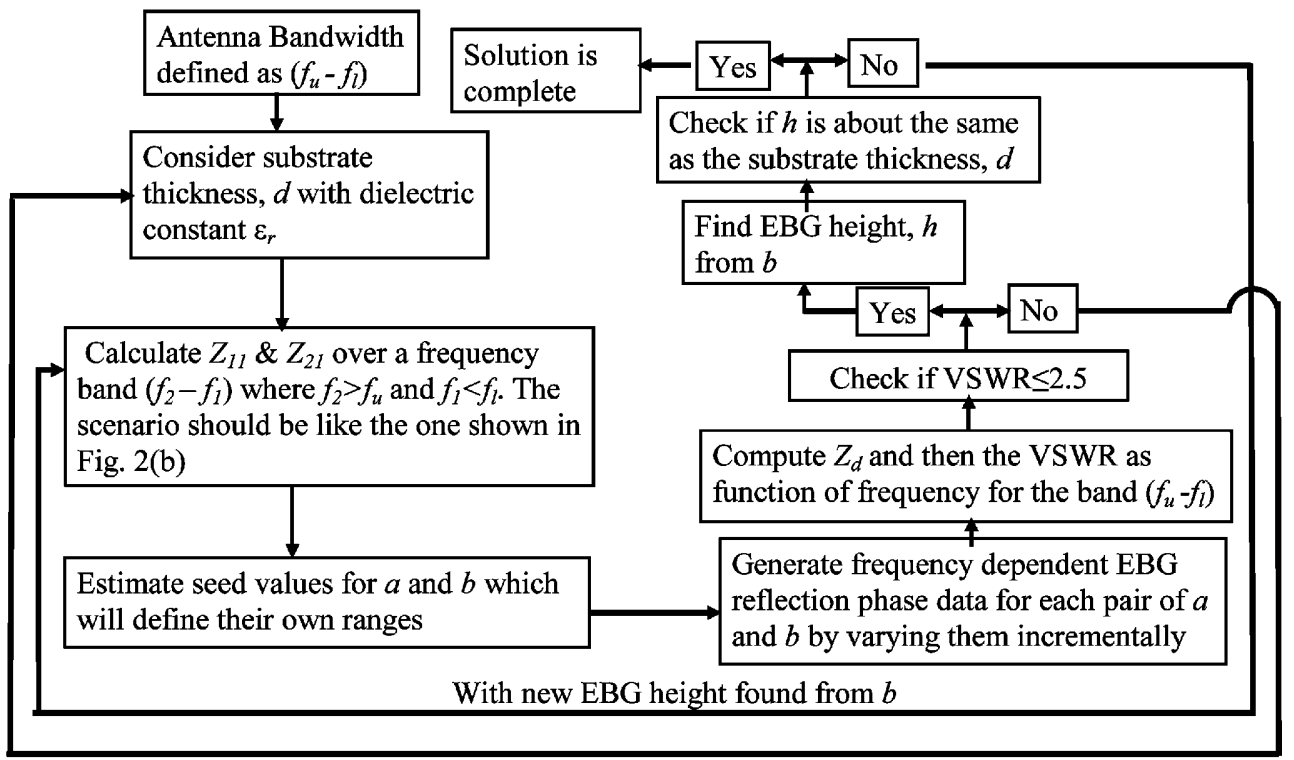

With dipole resonant frequency greater than the initial one

Fig. 8. Flow chart of the design process.

difference of the order of 5 degrees or less is observed at some frequencies.

\section{PRINTED Wide BAND Dipole On AN EBG StRucture}

\section{A. Design Basics}

The goal of this study is to design a wideband directional dipole antenna on an EBG structure. To isolate the dipole from the EBG surface we plan to use a thin separating layer of dielectric material between the antenna and the EBG as shown in Fig. 7. Consider the antenna bandwidth to be defined as $\left(f_{u}-f_{l}\right)$, where $f_{l}$ and $f_{u}$ are the low and high frequencies, respectively. Antenna bandwidth must satisfy a VSWR upper limit, for instance 2.5:1. Note that since the dipole is printed on a very thin dielectric layer we consider the antenna height and the EBG thickness to be the same which is $h$ (see Fig. 7). The design process can be summarized as follows.

a) Consider a printed dipole antenna on a substrate with dielectric constant, $\epsilon_{r}$ and substrate thickness, $d$. The resonant frequency of the dipole is within the frequency band of operation. The configuration is similar to Fig. 2. Consider the equivalent case for the printed dipole antenna shown in Fig. 2(b).

b) Develop simulation models using HFSS or some other solver representing the scenario in Fig. 2(b). Compute $Z_{11}$ and $Z_{21}$ for the two dipoles for a frequency range of $\left(f_{2}-\right.$ $f_{1}$ ) where $f_{2}>f_{u}$ and $f_{1}<f_{l}$. This is to ensure that the impedance data are computed over a wider band than the required bandwidth $\left(f_{u}-f_{l}\right)$ defined above.

c) Generate frequency dependent EBG reflection phase data, $\theta$. Follow the steps listed below.

d) Estimate seed values for the parameters $a$ and $b$. The two seed values for $a$ defines its range while the two seed values for $b$ defines its range. Perform a simple Matlab simulation by varying $a$ and $b$ incrementally within their respective ranges. Each $a$ and $b$ pair will represent a specific EBG reflection phase profile. Now apply (1) to compute $Z_{d}$ and then the VSWR as function of frequency for the band $\left(f_{u}-f_{l}\right)$.

e) If a solution is found within VSWR limit 2.5:1 check the value of the parameter $b$ that provides such solution. Since $b$ corresponds to EBG height $h$, check if this new $h$ corresponds to the initial dipole height, $d$.

f) If the EBG height, $h$ is about same as the dipole antenna height the solution is complete.

g) If not start from (a) with the new EBG height corresponding to $b$ found in (e).

h) If step (d) does not provide any feasible value of $a$ and $b$ we have to start over from (a) with a new dipole resonant frequency greater than the initial one.

A flow chart of this design process is shown in Fig. 8.

\section{B. Seed Values of Parameters $a$ and $b$}

We know that we cannot choose arbitrary initial and final values for the parameters $a$ and $b$ because the true $a$ and $b$ values which may give wideband antenna performance may fall outside such ranges. In that case no suitable solution will be found.

To find an appropriate range for $a$ and $b$, consider $f_{1}=0.67 f_{l}$ and $f_{2}=1.2 f_{u}$. Also consider two seed EBG heights for each of these frequencies, one smaller and the other greater than the assumed antenna height at the beginning. These two seed EBG heights can be used to find $L$ and $b$ using (4) and (3). The frequency at which the EBG reflection phase is 0 degree can be calculated from

$$
f=\frac{1}{2 \pi \sqrt{L C}} .
$$

For each seed EBG height $C$ can be calculated using (6) and $a$ from (3). 
TABLE I

SELECTING THE INITIAL AND FINAL VALUES OF PARAMETERS a AND b

\begin{tabular}{|c|c|c|c|c|c|}
\hline & & \multicolumn{2}{|c|}{$1 \mathrm{GHz}$} & \multicolumn{2}{c|}{$3 \mathrm{GHz}$} \\
\hline$h(\mathrm{~mm})$ & & 1 & 10 & 1 & 10 \\
\hline$L(\mathrm{nH})$ & use (4) to get $L$ & 1.256 & 12.56 & 1.256 & 12.56 \\
\hline$b \times 10^{-8}$ & use (3) to get $b$ & 0.789 & 7.89 & 0.789 & 7.89 \\
\hline$C(\mathrm{pF})$ & use(6) to get $C$ & 20.15 & 2.015 & 2.24 & 0.224 \\
\hline$a \times 10^{-17}$ & use (3) to get $a$ & 37.7 & 37.7 & 4.18 & 4.18 \\
\hline
\end{tabular}

TABLE II

\begin{tabular}{|c|c|c|c|c|c|}
\hline TMM & \multicolumn{2}{|c|}{$\begin{array}{c}f_{\text {res }}=1.65 \\
(\mathrm{GHz})\end{array}$} & \multicolumn{2}{c|}{$\begin{array}{c}f_{\text {res }}=1.75 \\
(\mathrm{GHz})\end{array}$} & $\begin{array}{c}f_{\text {res }}=1.85 \\
(\mathrm{GHz})\end{array}$ \\
\hline$d(\mathrm{~mm})$ & 2 & 3 & 2 & 3 & 2 \\
\hline Solutions for $a$ and $b$ & No & No & No & No & Yes \\
\hline
\end{tabular}

\section{Specific Design Example}

Let us assume that we want to design a wideband directional dipole antenna on an EBG structure that can operate from a frequency of 1.65 to $2.4 \mathrm{GHz}$. Such a wide frequency band will include the DCS, PCS, GSM 1900, UMTS and IEEE802.11b. To ensure that the final dipole design satisfies this bandwidth within 2.5:1 VSWR let us consider $f_{1}=1 \mathrm{GHz}$ and $f_{2}=3$ $\mathrm{GHz}$ according to the guidelines established in Section IV-B. Also consider EBG seed heights, $h$ of $1 \mathrm{~mm}$ and $10 \mathrm{~mm}$, respectively. Table I shows the initial and final values of the parameters $a$ and $b$ within such constrains. Parameter $a$ should lie within $4 \times 10^{-17}$ to $38 \times 10^{-17}$ while parameter $b$ should lie within $0.8 \times 10^{-8}$ to $8 \times 10^{-8}$.

Consider a dipole antenna printed on a TMM $\left(\epsilon_{r}=4.5\right)$ substrate $(94 \mathrm{~mm} \times 94 \mathrm{~mm})$. The dipole was made of two metal strips with $1 \mathrm{~mm}$ width and $45.7 \mathrm{~mm}$ length. The step size chosen for $a$ and $b$ was $\Delta a=0.1 \times 10^{-17}$ and $\Delta b=0.1 \times$ $10^{-8}$ respectively. Considering dipole resonant frequency of $1.65 \mathrm{GHz}$ and a height, $d=2 \mathrm{~mm}$ no solution was found for which wideband operation can be achieved. This is noted in Table II. Similarly no solution was found for the same antenna for $d=3 \mathrm{~mm}$. The same situation repeated when we used a dipole antenna that was resonant at $1.75 \mathrm{GHz}$. However, next when we used a dipole antenna resonant at $1.85 \mathrm{GHz}$ a solution was found for $d=2 \mathrm{~mm}$. For the dipole resonant at 1.85 $\mathrm{GHz}$ the computed results are listed in Table III. Note that for $d=2 \mathrm{~mm}$ the Matlab optimization program suggests an EBG height, $h=4.1 \mathrm{~mm}$. Now when we compute the impedances for a dipole with $d=4.1 \mathrm{~mm}$ our EBG optimization program suggests a new EBG height of $5.1 \mathrm{~mm}$. This process is repeated as shown in Table III until $d$ and $h$ are very close or nearly the same. Thus our final results show that $d=h=5.9 \mathrm{~mm}$ should result in a wideband dipole antenna design.

\section{REsults}

\section{A. Wideband Dipole on TMM}

The EBG parameters that resulted in wideband antenna performance are $a=8.8 \times 10^{-17}, b=4.7 \times 10^{-8}, h=$
TABLE III

\begin{tabular}{|c|c|c|c|c|}
\hline TMM & \multicolumn{4}{|c|}{$f_{\text {res }}=1.85 \mathrm{GHz}$} \\
\hline$d(\mathrm{~mm})$ & 2 & 4.1 & 5.1 & 5.9 \\
\hline$h(\mathrm{~mm})$ & 4.1 & 5.1 & 5.9 & 5.9 \\
\hline
\end{tabular}

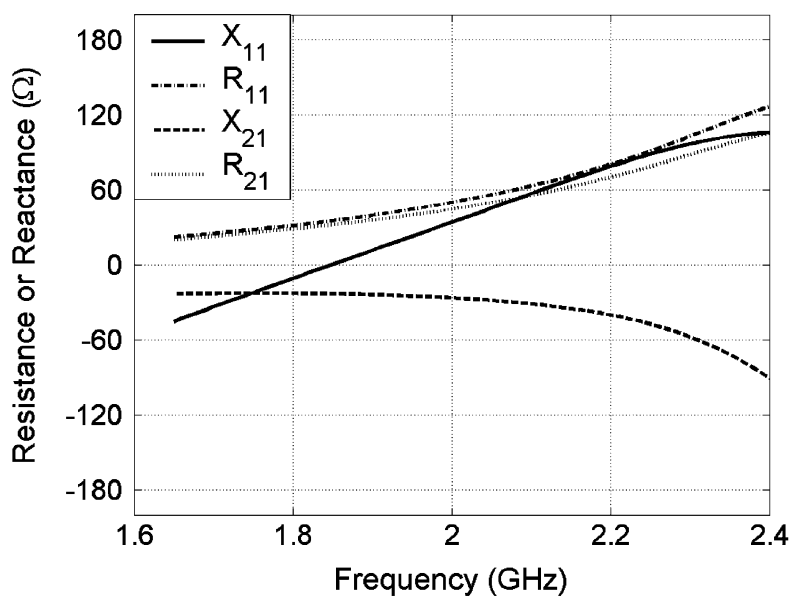

(a)

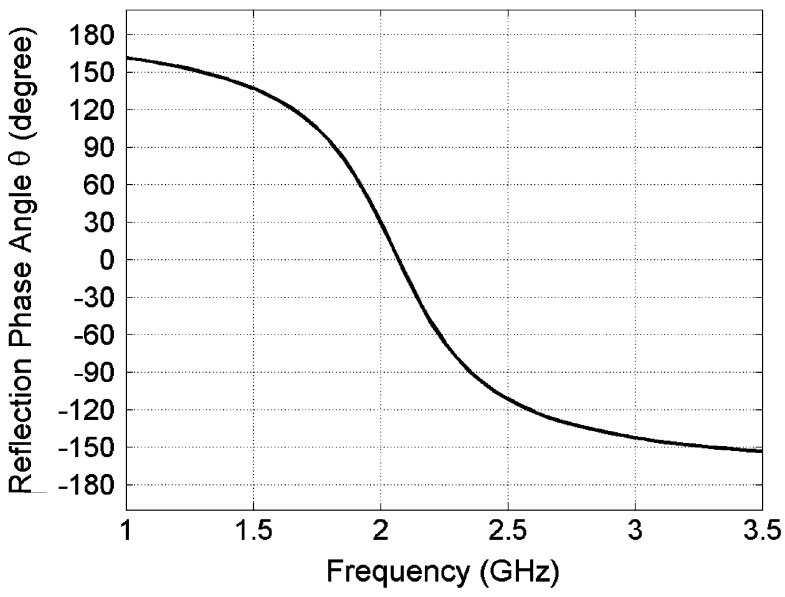

(b)

Fig. 9. (a) Self and mutual impedance data of dipole antennas on $11.8 \mathrm{~mm}$ thick TMM substrate and (b) optimized EBG reflection phase.

$5.9 \mathrm{~mm}, g=0.4 \mathrm{~mm}$ and $w=12.4 \mathrm{~mm}$. Self and mutual impedance data of the dipoles placed $11.8 \mathrm{~mm}$ apart from each other on the TMM substrate is shown in Fig. 9(a). The dipole resonant frequency is $1.85 \mathrm{GHz}$. Reflection phase versus frequency curve for this optimized EBG structure is shown in Fig. 9(b).

The VSWR data obtained using the proposed technique are compared with direct simulation results from HFSS in Fig. 10. For the direct simulation the dipole was placed on a $0.1 \mathrm{~mm}$ thick Rohacell Foam. The mushroom EBG structure underneath the foam substrate consisted of 8 by 6 cells. In both cases dual band characteristics are observed. Considering a 2.5:1 VSWR upper limit results using our method indicate a $40 \%$ bandwidth while the direct results from HFSS indicate $37 \%$ bandwidth. Direct results from HFSS simulation show a slightly higher frequency of operation than that obtained using the proposed tech- 


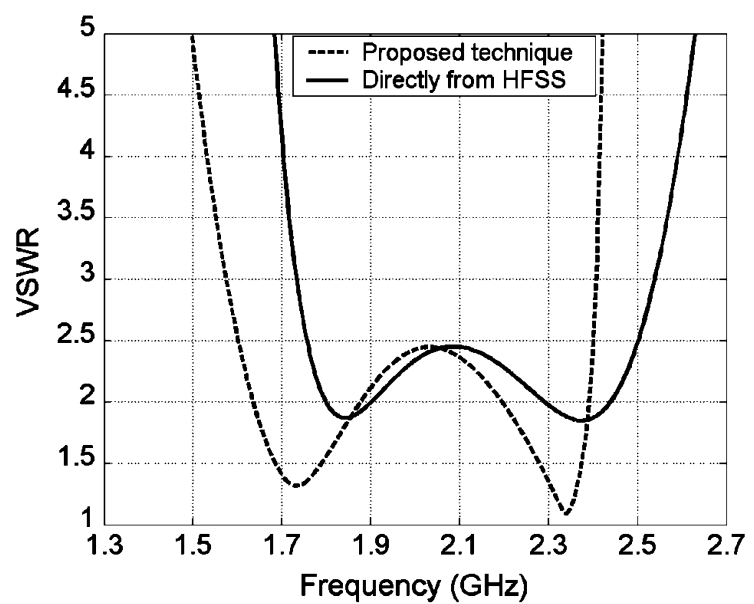

Fig. 10. Optimum VSWR characteristics of a printed dipole antenna on an EBG structure.

TABLE IV

EBG DESIGN PARAMETERS

\begin{tabular}{|c|c|c|c|c|c|c|c|}
\hline $\begin{array}{c}\text { Subs } \\
\left(\varepsilon_{\mathrm{r}}\right)\end{array}$ & $\begin{array}{c}\text { Design } \\
\text { parameter } \\
a \times 10^{-17}\end{array}$ & $\begin{array}{c}\text { Design } \\
\text { parameter } \\
b \times 10^{-8}\end{array}$ & $\begin{array}{c}L \\
\mathrm{nH}\end{array}$ & $\begin{array}{c}C \\
\mathrm{pF}\end{array}$ & $\begin{array}{c}\mathrm{EBG} \\
\mathrm{mm}\end{array}$ & $\begin{array}{c}\text { Gap } \\
\mathrm{mm} \\
\mathrm{mm}\end{array}$ & $\begin{array}{c}\text { Width } \\
\text { of } \\
\mathrm{EBG} \\
w \mathrm{~mm}\end{array}$ \\
\hline 3.5 & 8.8 & 4.7 & 7.5 & 0.78 & 6.0 & 0.4 & 14.4 \\
\hline 2.2 & 9.4 & 5.5 & 8.8 & 0.72 & 7.0 & 0.4 & 17.7 \\
\hline
\end{tabular}

nique. Also the generally low VSWR values observed using our proposed method is not seen in the direct HFSS simulation results. These discrepancies can be attributed to the simple assumptions made considering the real and image dipoles shown in Fig. 2.

\section{B. Antennas on other Dielectric Substrates}

The same optimization process was carried out for antennas and EBGs on other substrates: substrate $1\left(\epsilon_{r}=3.5\right)$ and substrate2 $\left(\epsilon_{r}=2.2\right)$ also. Optimized values of EBG parameters for each substrate are listed in Table IV. Note that the EBG plate sizes on these low dielectric constant substrates are larger than that on the TMM substrate $\left(12.4 \times 12.4 \mathrm{~mm}^{2}\right)$.

Corresponding simulated VSWR data for these two cases are shown in Fig. 11. The bandwidths of the dipole are $34 \%$ and $32 \%$ respectively on substrate 1 and substrate2. These numbers are slightly smaller than what was obtained with TMM.

\section{Wideband Printed Balun}

When a balanced antenna (dipole) is connected to a coaxial transmission line, the transition from the feed line to the balanced antenna is an unbalanced driven system. This generally causes pattern degradation since the outside shield of the coax radiates. A balun is used between the feed line and the antenna to solve this problem. For our purpose we need a wide band balun [23], [24] operating from 1.6 to $2.5 \mathrm{GHz}$.

The prototype of the wideband planar balun used in this paper is shown in Fig. 12. The balun structure output contains two signals with the same magnitude but $180^{\circ}$ phase difference. It

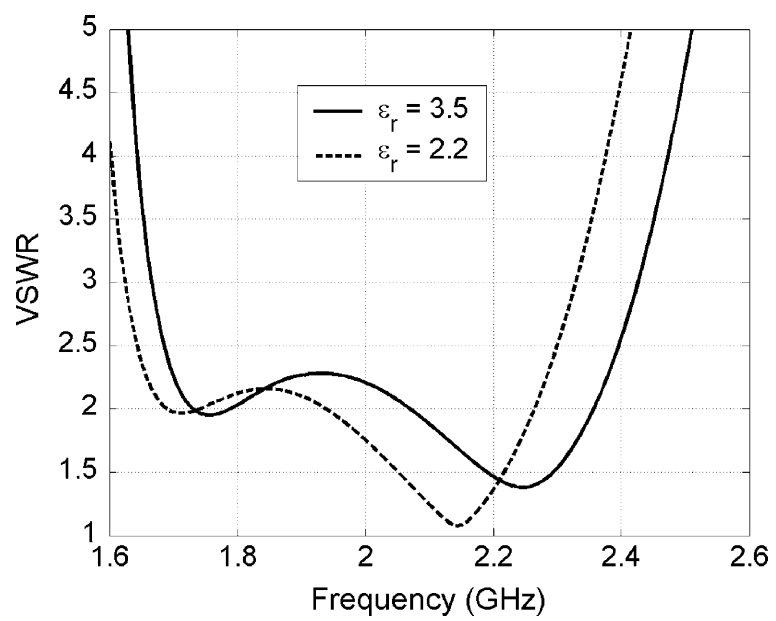

Fig. 11. Computed VSWR data of a printed dipole on optimized EBG structures with $\epsilon_{r}=3.5$ and $\epsilon_{r}=2.2$.

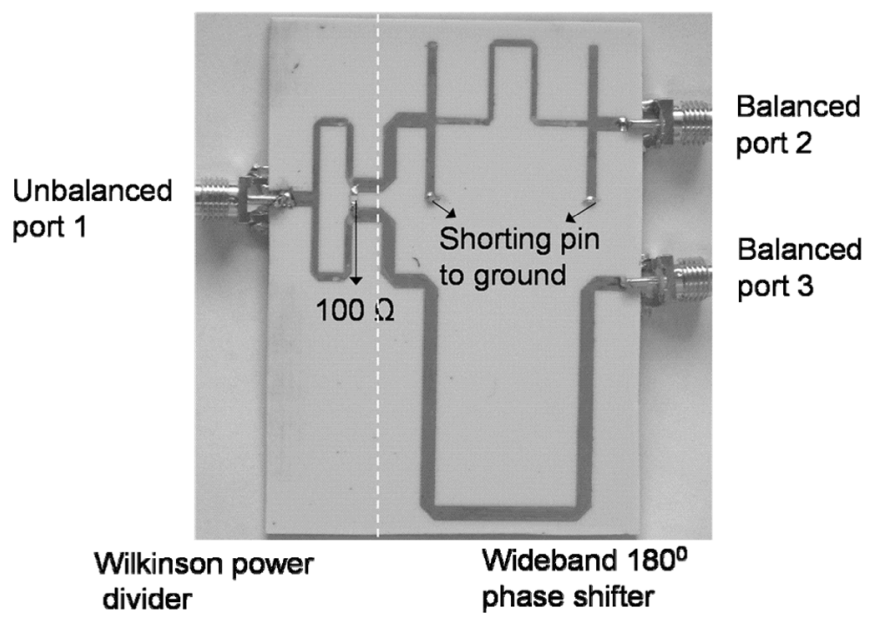

Fig. 12. Photograph of wideband planar balun.

consists of a $3 \mathrm{~dB}$ Wilkinson power divider [25] and a non-coupled line broad band $180^{\circ}$ phase shifter [26] as shown in Fig. 12. Fig. 13 displays the simulated and measured return loss and isolation characteristics of the balun. The measured return losses of the unbalanced port as well as the balanced ports are better than $-15 \mathrm{~dB}$ from 1.6-2.5 GHz. The simulated and measured amplitude imbalances between the two balanced ports are within $0.5 \mathrm{~dB}$. As apparent from Fig. 14 the phase difference between the two balanced ports of the balun is close to $180^{\circ}$. Measured phase balance is within plus minus 5 degrees of the simulation which is excellent.

\section{Printed Dipole on EBG with Balun}

1) VSWR Characteristics: The above wideband balun was used to feed the printed dipole antenna on the TMM based EBG structure. The complete stack up is shown in Fig. 15(a). The EBG structure as stated in Section V-A was printed on a 6.0 mm thick grounded TMM substrate $\left(\epsilon_{r}=4.5\right)$. As shown in Fig. 15(a) the printed wideband balun was placed below the EBG ground plane. The balun was printed on a $0.8 \mathrm{~mm}$ thick Rogers RO4003 substrate $\left(\epsilon_{r}=3.38\right)$. Thus the EBG ground plane and the balun ground plane were touching. Alternatively 


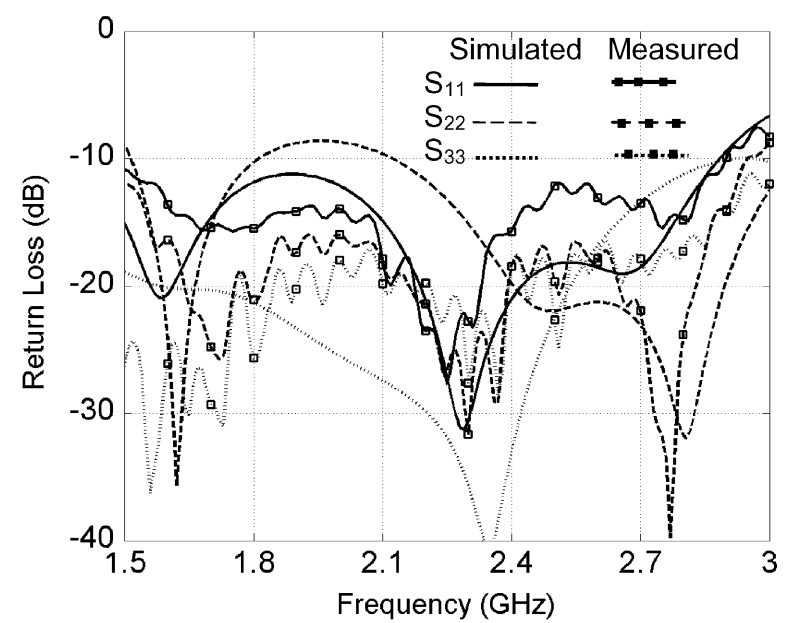

(a)

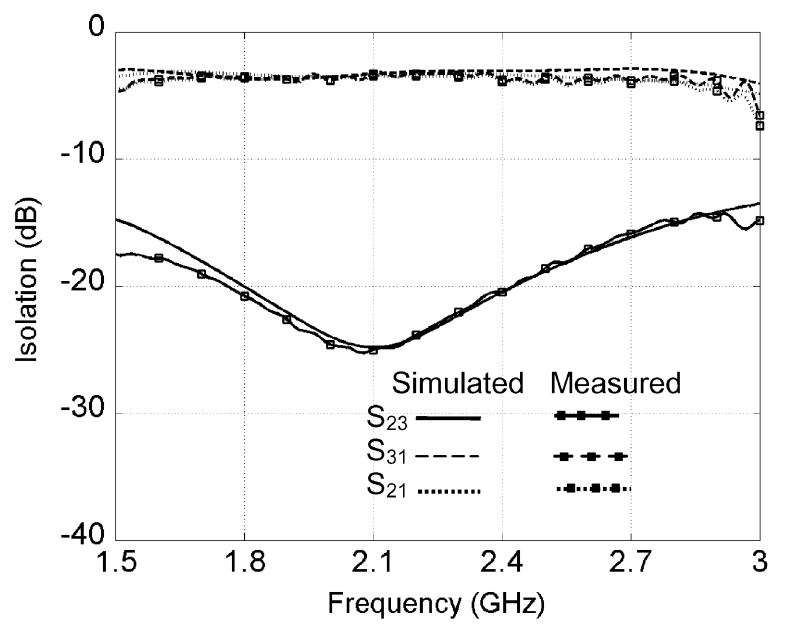

(b)

Fig. 13. (a) Return loss and (b) isolation data of the printed wideband balun.

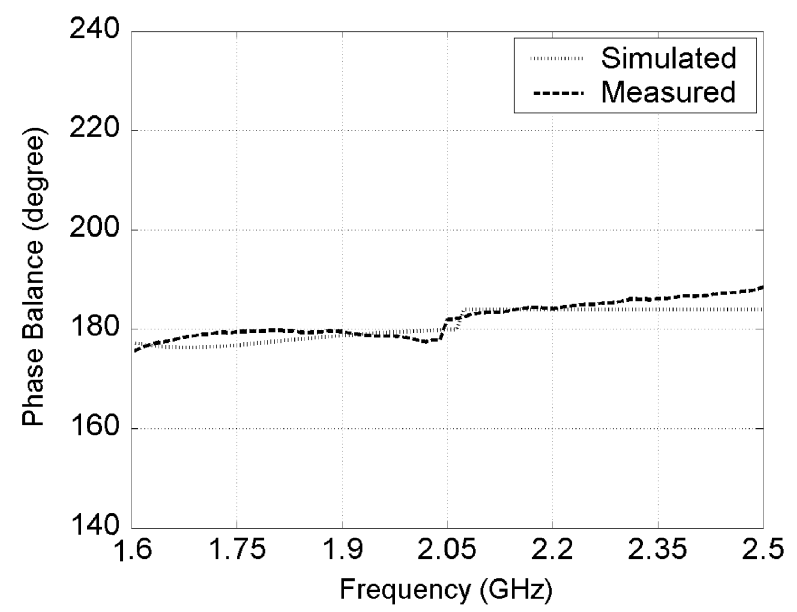

Fig. 14. Simulated and measured phase difference between the two balanced ports.

the balun and EBG will share one ground plane when manufactured for practical application. A dipole antenna of strip length $45.7 \mathrm{~mm}$ and strip width $1.0 \mathrm{~mm}$ was printed on a $0.1 \mathrm{~mm}$ thick RO4003 substrate and then placed on the EBG structure. Two

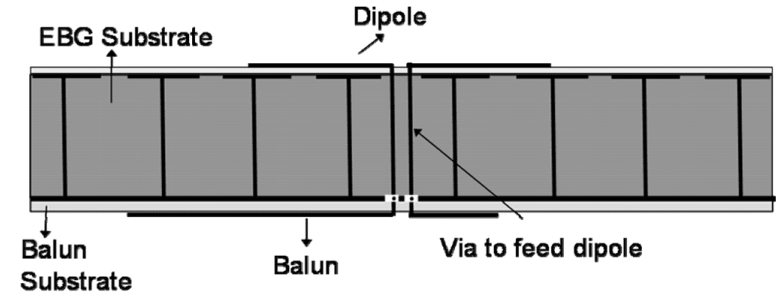

(a)

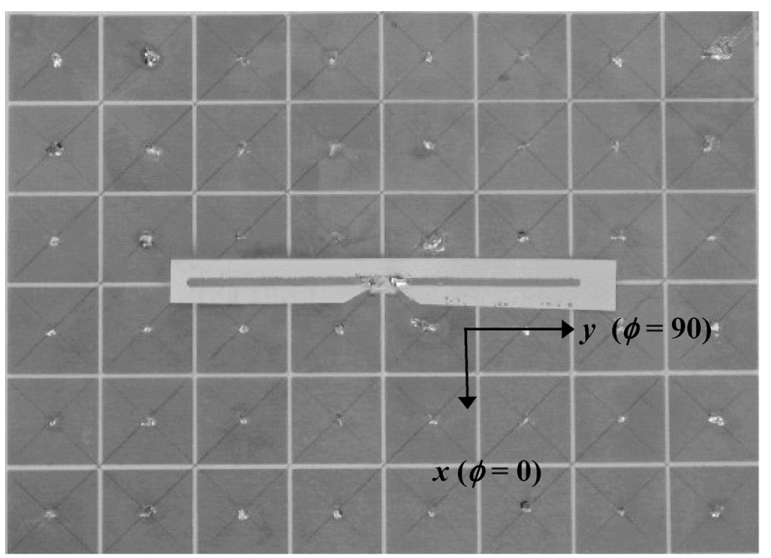

(b)

Fig. 15. (a) Feeding technique of dipole with planar balun and (b) fabricated EBG with dipole.

holes $($ diameter $=1.2 \mathrm{~mm})$ were drilled within the EBG and the balun substrates. The two balanced ports of the balun were then connected to the two arms of the dipole using vias as shown in Fig. 15(a). These vias should not touch the ground plane while passing through the hole. The holes removed only very small portions of the nearby EBG plates. The fabricated prototype of the EBG with the printed dipole antenna is shown in Fig. 15(b).

Measured VSWR data with the printed wideband balun are compared with simulated data with and without the balun in Fig. 16. The simulated and measured data with the balun show wider bandwidth compared to the simulation data without the balun. The simulated and measured bandwidths with the balun are $38 \%$ and $41 \%$ respectively. Note that the balun characteristics influence the antenna input impedance and return loss and hence even though the measured VSWR data show performance extending from $1.5-2.5 \mathrm{GHz}$ the antenna gain characteristics will show that the actual antenna operation band is from $1.75-2.5 \mathrm{GHz}$.

2) Radiation Characteristics: Computed normalized radiation patterns of the printed dipole antenna on the EBG structure are shown in Fig. 17. The geometry corresponding to the antenna is shown in Fig. 15. The dipole is placed along the $y$-axis. Patterns were computed at 1800, 2100, and $2400 \mathrm{MHz}$. At all frequencies the patterns are directional as expected. The $\phi=0^{\circ}$ plane represents the plane orthogonal to the dipole axis while the $\phi=90^{\circ}$ degree plane represents the plane parallel to the dipole axis [see Fig. 15(b)]. In each plane the radiation beam is directed broadside $\left(\theta=0^{\circ}\right)$. The beam shapes at the two principal planes are very similar and the cross-polarization is generally below $-20 \mathrm{~dB}$. 


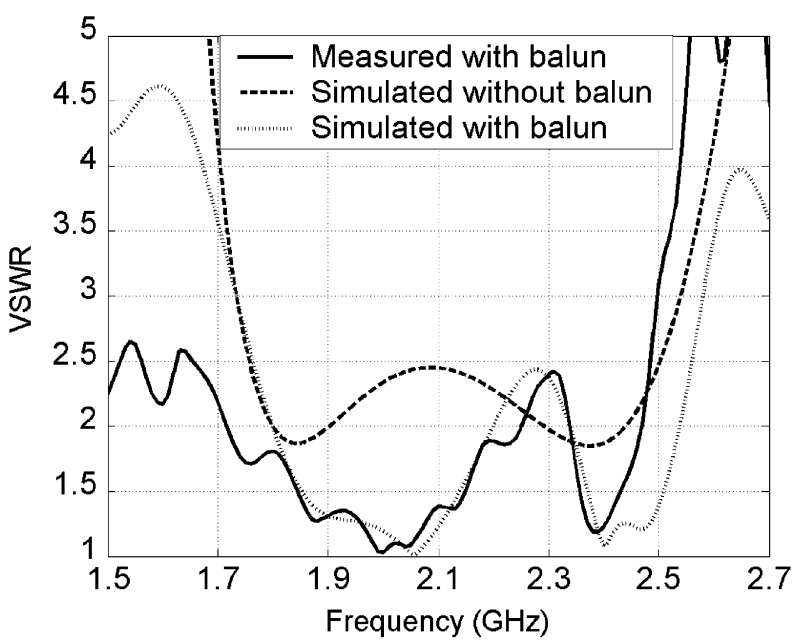

Fig. 16. Computed and measured VSWR characteristics of the dipole on EBG.

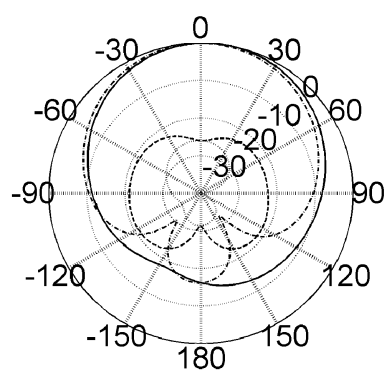

(a)

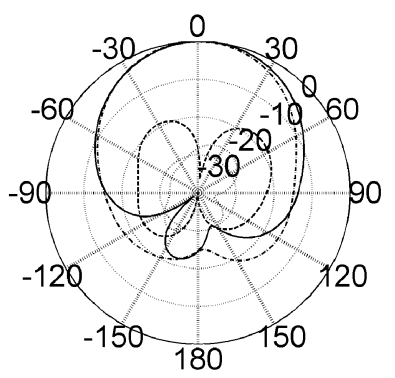

(c)

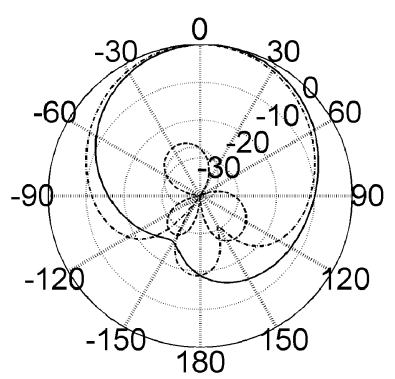

(b)

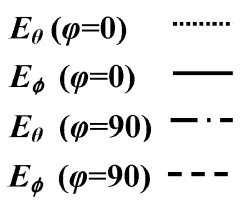

Fig. 17. Computed normalized radiation patterns of the proposed dipole on the EBG structure at (a) $1800 \mathrm{MHz}$, (b) $2100 \mathrm{MHz}$ and (c) $2400 \mathrm{MHz}$; substrate: TMM.

Fig. 18 shows the computed peak gain and the front to back (F/B) ratio. Peak gain increases from $5.5 \mathrm{dBi}$ to $8.3 \mathrm{dBi}$ as frequency increases from $1.7 \mathrm{GHz}$ to $2.5 \mathrm{GHz}$. Peak gain is 6.0 , 7.2, and $8.0 \mathrm{dBi}$ at $1800 \mathrm{MHz}, 2100 \mathrm{MHz}$ and $2400 \mathrm{MHz}$, respectively. The front to back $(\mathrm{F} / \mathrm{B})$ ratio ranges from $16 \mathrm{~dB}$ to $26 \mathrm{~dB}$.

\section{CONCLUSION}

A new technique to design a printed wideband directional dipole antenna on EBG structures is introduced. By optimizing the interaction between the impedances of a primary and image dipoles with the reflection phase of a mushroom like EBG structure a wideband printed dipole antenna was designed, fabricated, and measured. The antenna can support DCS, PCS,

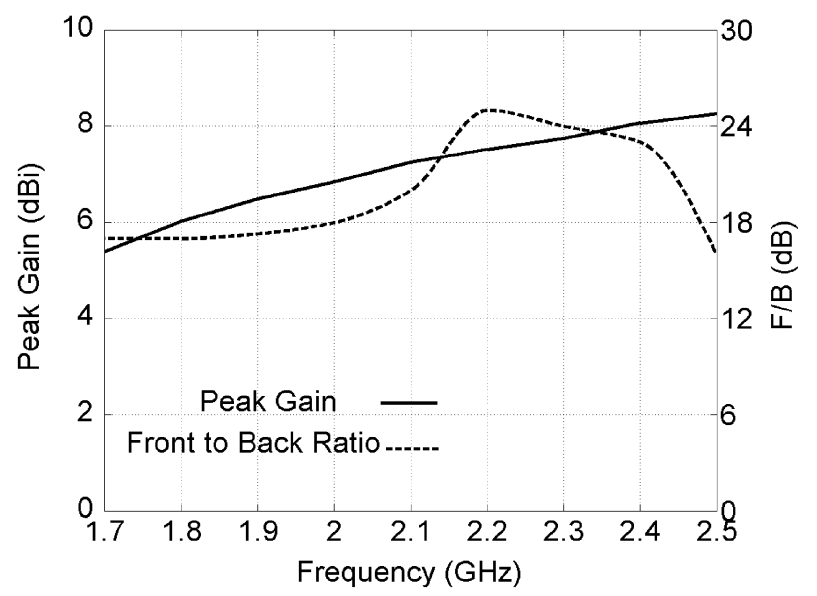

Fig. 18. Peak gain and front to back ratio versus frequency data.

UMTS, and IEEE 802.11b applications within 2.5:1 VSWR. Since the space availability in mobile phones or other small handheld terminals for antennas is minimal our proposed wideband directional dipole antenna is more appropriate for wireless base stations and other fixed wireless stations which can benefit from a thin profile and wideband characteristics. The peak gain of the balun-fed antenna ranges from 5.5 to 8.3 $\mathrm{dBi}$ and the front to back ratio $(\mathrm{F} / \mathrm{B})$ is better than $16 \mathrm{~dB}$ within this frequency range. The proposed design technique can be easily adapted to design printed wideband directional dipoles at other frequencies. We have studied the antenna bandwidth for two other EBG heights, $5.4 \mathrm{~mm}$ and $6.4 \mathrm{~mm}$. Note that our optimized EBG height is $5.9 \mathrm{~mm}$. The $\pm 0.5 \mathrm{~mm}$ tolerance in the EBG height does not show any significant deviation in bandwidth. A small shift in operation frequency is observed for the smaller height along with lower VSWR. In essence for any optimized design one needs to perform a tolerance analysis based on the available substrate thickness. If the optimized substrate thickness is unavailable and the substrate dielectric constant and thickness deviate significantly then a design compromise must be made to arrive at a cost-effective solution.

\section{REFERENCES}

[1] F. Yang, X. X. Zhang, Y. Xiaoning, and Y. Rahmat-Samii, "Wide-band E-shaped patch antennas for wireless communications," IEEE Trans. Antennas Propag., vol. 49, pp. 1094-1100, Jul. 2001.

[2] W. L. Stutzman and G. A. Thiele, Antenna Theory and Design, 2nd ed. New York: Wiley, 1998.

[3] C. Balanis, Antenna Theory, Analysis, and Design, 2nd ed. New York: John Wiley and Sons, 1997.

[4] D. F. Sievenpiper, "High impedance electromagnetic surfaces," Ph.D. dissertation, Univ. California, Los Angeles, 1999.

[5] J. M. Bell and M. F. Iskander, "A low-profile Archimedean spiral antenna using an EBG ground plane," IEEE Antennas Wireless Propag. Lett., vol. 3, pp. 223-226, 2004.

[6] R. F. J. Broas, D. F. Sievenpiper, and E. Yablonovitch, "A high-impedance ground plane applied to a cell-phone handset geometry," IEEE Trans. Microw. Theory Tech., vol. 49, no. 7, pp. 1262-1265, Jul. 2001.

[7] F. Yang and Y. Rahmat-Samii, "Mutual coupling reduction of microstrip antennas using electromagnetic band-gap structure," in Proc. IEEE AP-S Int. Symp. Dig., Jul. 2001, vol. 2, pp. 478-481.

[8] M. Rahman and M. Stuchly, "Wide-band microstrip patch antenna with planar PBG structure," in Proc. IEEE AP-S Int. Symp. Dig., Jul. 2001, vol. 2, pp. 486-489. 
[9] S. Sharma and L. Shafai, "Enhanced performance of an aperture-coupled rectangular microstrip antenna on a simplified uniplanar compact photonic bandgap (UCPBG) structure," in Proc. IEEE AP-S Int. Symp. Dig., Jul. 2001, vol. 2, pp. 498-501.

[10] F. Yang and Y. Rahmat-Samii, "Microstrip antennas integrated with electromagnetic band-gap (EBG) structures: A low mutual coupling design for array applications," IEEE Trans. Antennas Propag., vol. 51, pp. 2939-2949, Oct. 2003.

[11] H. Mosallaei and K. Sarabandi, "Antenna miniaturization and bandwidth enhancement using a reactive impedance substrate," IEEE Trans. Antennas Propag., vol. 52, no. 9, pp. 2403-2414, Sep. 2004.

[12] R. C. Hansen, "Effects of a high-impedance screen on a dipole antenna," IEEE Antennas Wireless Propag. Lett., vol. 1, pp. 46-49, 2002.

[13] F. Yang and Y. Rahmat-Samii, "Reflection phase characterizations of the EBG ground plane for low profile wire antenna applications," IEEE Trans. Antennas Propag., vol. 51, no. 10, pp. 2691-2703, Oct. 2003.

[14] M. Martinez and R. Baggen, "Characterisation of printed EBG surfaces for GPS application," in Proc. IEEE Int. Workshop on Antenna Technology: Small Antennas and Novel Metamaterials, New York, Mar. 2006, pp. 5-8.

[15] M. F. Abedin and M. Ali, "Effects of EBG reflection phase profiles on the input impedance and bandwidth of ultra-thin directional dipoles," IEEE Trans. Antennas Propag., vol. 53, no. 11, pp. 3664-3672, Nov. 2005.

[16] Y. J. Park, A. Herschlein, and W. Wiesbeck, "A photonic bandgap (PBG) structure for guiding and suppressing surface waves in millimeter-wave antennas," IEEE Trans. Microw. Theory Tech, vol. 49, no. 10, pp. 1854-1859, Oct. 2001.

[17] D. Pavlickovski and R. B. Waterhouse, "Shorted microstrip antenna on a photonic bandgap substrate," IEEE Trans. Antennas Propag., vol. 51, no. 9, pp. 2472-2475, Sep. 2003.

[18] D. Sievenpiper, L. Zhang, R. F. J. Broas, N. G. Alexopolous, and E. Yablonovitch, "High impedance electromagnetic surfaces with a forbidden frequency band," IEEE Trans. Microw. Theory Tech, vol. 47, no. 11, pp. 2059-2074, Nov. 1999.

[19] R. Gonzalo, P. Maaget, and M. Sorolla, "Enhanced patch-antenna performance by suppressing surface waves using photonic-bangdap substrates," IEEE Trans. Microw. Theory Tech., vol. 47, pp. 2131-2138, Nov. 1999.

[20] K. C. Huie, "Microstrip antenna: broadside radiation patterns using photonic crystal substrate," M.Sc. Dissertation, Virginia Polytechnic Institute and State University, Blacksburg, 2002.

[21] V. Radisic, Y. Qian, R. Coccioli, and T. Itoh, "A novel 2-D photonic bandgap structure for microstrip lines," IEEE Microw.Guided Wave Lett., vol. 8, pp. 69-71, Feb. 1998.

[22] L. Yang, M. Fan, F. Chen, J. She, and Z. Feng, "A novel compact electromagnetic bandgap (EBG) structure and its applications for microwave circuits," IEEE Trans. Microw. Theory Tech, vol. 53, no. 1, pp. 183-190, Jan. 2005.

[23] K. V. Puglia, "Electromagnetic simulation of some common balun structures," IEEE Microw. Mag., pp. 56-61, Sep. 2002.

[24] Z. Y. Zhang, Y. X. Guo, L. C. Ong, and M. Y. W. Chai, "A new wide-band planar balun on a single layer PCB," IEEE Microw. Wireless Comp. Lett., vol. 15, no. 6, pp. 414-418, Jun. 2005.
[25] E. Wilkinson, “An N-Way hybrid power divider," IRE Trans. Microw. Theory Tech., vol. vol. MTT-8, pp. 116-118, Jan. 1960.

[26] S. Y. Eom, S. I. Jeon, J. S. Chae, and J. G. Yook, "Broadband 180 bit phase shifter using a new switched network," in Proc. IEEE MTT-S Int. Symp. Dig., Jun. 2003, vol. 1, pp. 39-42.

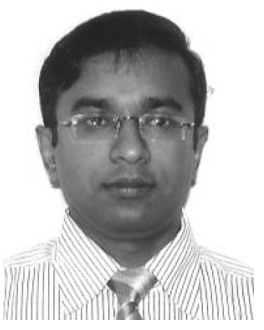

Mohammed Ziaul Azad (S'05) was born in Dhaka, Bangladesh, in 1977. He received the B.Sc. degree from Bangladesh University of Engineering and Technology, Dhaka, in 2002 and the M.S.E.E. degree from the University of South Carolina, Columbia, in 2007, respectively, all in electrical engineering. He is currently working towards the Ph.D. degree at the University of South Carolina.

$\mathrm{He}$ is the author or coauthor of several refereed journal articles and conference papers. His research interests include antenna miniaturization, diversity antennas, mobile phone and WLAN antennas, GPS antennas, filters, electromagnetic bandgap (EBG) structures and their antenna applications.

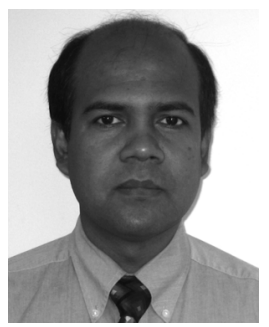

Mohammod Ali (M'93-SM'03) received the B.Sc. degree in electrical and electronic engineering from the Bangladesh University of Engineering and Technology, Dhaka, Bangladesh, in 1987, and the M.A.Sc. and Ph.D. degrees, both in electrical engineering, from the University of Victoria, Victoria, BC, Canada, in 1994 and 1997, respectively.

He was with the Bangladesh Institute of Technology, Chittagong, from 1988 to 1992. From January 1998 to August 2001, he was with Ericsson Inc., Research Triangle Park, NC, first as a Staff Engineer and then as a Senior Staff Engineer. Since August 2001, he has been with the Department of Electrical Engineering, University of South Carolina, Columbia, where currently he is an Associate Professor. He had also held appointments as a Visiting Research Scientist with the Motorola Corporate EME Research Laboratory, Plantation, FL, during June to August 2004. He is the author/coauthor of over 90 journal and conference publications and holds five U.S. patents. His research interests include miniaturized packaged (embedded) antennas, metamaterials and their antenna applications, distributed wireless sensors and rectennas, reconfigurable antennas, and portable/wearable antennas and their interactions with humans (SAR).

Dr. Ali is the recipient of the 2003 National Science Foundation Faculty Career Award. He is also the recipient of the College of Engineering and Information Technology Young Investigator Award from the University of South Carolina in 2006. He is an Associate Editor of the journal IEEE Antennas and Wireless Propagation Letters. 